\title{
MODELO ANALÍTICO DEL DERECHO DE INFORMACIÓN DE LOS REPRESENTANTES DE LOS TRABAJADORES Y VALORACIÓN DE SU RECONOCIMIENTO EN CHILE*
}

\author{
ANALYTICAL MODEL OF THE WORKERS REPRESENTATIVES' \\ RIGHT OF INFORMATION AND VALUATION \\ OF ITS ACKNOWLEDGEMENT IN CHILE
}
LE MODELE ANALYTIQUE DU DROIT A L'INFORMATION
DES REPRESENTANTS DES TRAVAILLEURS

ET UNE EVALUATION DE SA RECONNAISSANCE AU CHILI

\section{Rodrigo PALOMO VÉLEZ ${ }^{* *}$}

\begin{abstract}
RESUMEN: El derecho de información, además de constituir una importante prerrogativa de la representación colectiva de los trabajadores, tiene una naturaleza instrumental respecto del correcto desarrollo de otras competencias a las que sirve, por elevación, respecto de la propia función representativa. Su reconocimiento constituye, por tanto, un factor distintivo y de importancia vital en la adopción y consolidación de un modelo democrático de relaciones laborales.

En este trabajo se explican las bases dogmáticas del derecho de información de los representantes de los trabajadores, a partir de la comprensión de su fundamento jurídico y su naturaleza eminentemente instrumental. Luego, se identifican las principales fórmulas que concretan su reconocimiento normativo, proponiendo al efecto una matriz de ele-
\end{abstract}

* Recibido el 20 de marzo de 2017 y aprobado para su publicación el 4 de septiembre de 2017. Este artículo ha sido realizado en el marco de la ejecución del Proyecto Fondecyt de Iniciación núm. 11140484, titulado "Los derechos de información de los representantes de los trabajadores. Bases para reformular su reconocimiento jurídico en Chile", financiado por Conicyt.

** Profesor de Derecho del Trabajo, Investigador del Centro de Estudios de Derecho del Trabajo y de la Seguridad Social de la Universidad de Talca (Centrass). Correo electrónico: rpalomo@utalca.cl. 
mentos que permitan valorar tal reconocimiento en los diversos sistemas jurídicos y, en particular, en el chileno.

Palabras clave: derecho de información, libertad sindical, representación de los trabajadores, sindicato.

ABSTRACT: The right to information, besides of being an important prerogative for workers' collective representation, involves an instrumental nature regarding the proper development of other competencies, and because of that, about the representative function itself. Its acknowledgment then becomes a distinctive and vital factor in the path towards the adoption and consolidation of democratic labor relations model.

In this work the dogmatic foundations of the workers representative's right to information are explained, starting from the comprehension of its juridical grounds and eminently instrumental nature. The main formulas that set its legal acknowledgment are identified, and a number of elements that allow the evaluation of such acknowledgment throughout several juridical systems, particularly the Chilean one, are suggested.

Keywords: right to information, freedom of association, workers representation, trade union.

RÉSUMÉ: Le droit à l'information, en plus d'être une prérogative importante de la représentation collective des travailleurs, a une nature instrumentale par rapport au développement adéquat d'autres compétences qui le serve, mais également pour la fonction représentative. La reconnaissance de ce droit constitue un facteur distinctif, qui est d'une importance vitale pour l'adoption et la consolidation d'un modèle démocratique des relations de travail.

Le présent travail explique les bases dogmatiques du droit à l'information des travailleurs, à partir de la compréhension de sa base juridique et sa nature éminemment instrumentale. Ensuite sont identifiés les formules principales qui traduisent sa reconnaissance normative, en proposant une serié d'éléments qui permettent d'évaluer sa reconnaissance dans tous les systèmes juridiques, en particulier dans le système chilien.

Mots-clés: droit à l'information, liberté syndicale, représentation des travailleurs, syndicat. 
SUMARIO. I. Introducción. II. Las bases dogmáticas del derecho de información de los representantes de los trabajadores. III. Las principales fórmulas de reconocimiento normativo del derecho de información de los representantes de los trabajadores. IV. El derecho de información de los representantes de los trabajadores en Chile.

\section{Bibliografía.}

\section{INTRODUCCIÓN}

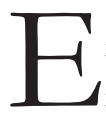
n el contexto de las relaciones laborales, los trabajadores, individualmente considerados, pueden ser titulares de diversos derechos de información, entendidos genéricamente como contrapartida de la obligación empresarial de informarles ciertas cuestiones, como su remuneración o la causa por la que se le despide.

Un fundamento y lógica de regulación distinta plantea, no obstante, el derecho de información con dimensión colectiva, objeto de este trabajo. En este caso, los sujetos destinatarios son los representantes de los trabajadores, y la causa o finalidad de su exigencia al empresario es permitir o facilitar la acción sindical. Dicho de otro modo, el derecho de información que ahora se analiza se ejercita por titulares especialmente cualificados para una actuación funcionalmente asociada: la representación de los trabajadores. ${ }^{1}$

En general, puede sostenerse que la discusión sobre las facilidades y garantías de la representación colectiva de los trabajadores en Latinoamérica ha estado postergada. Y es que ante el panorama imperante en los sistemas normativos de sindicalismo, que reclaman atención urgente e intensiva en la revisión de sus bases estructurales, la llamada "dimensión tutelar" de la organización de los trabajadores suele aparecer como una cuestión accesoria. Accesoria no en un sentido peyorativo, sino que en cuanto depende, en gran medida, de cómo se resuelvan los principales nudos de la institucionalidad orgánica y funcional del sindicalismo en nuestros países. ${ }^{2}$

1 Garrido, Eva, "La impronta del TJUE en el tratamiento español de los derechos de información y consulta, en especial en despidos colectivos”, Temas Laborales, España, núm. 130, 2015, p. 354.

2 En este sentido, Palomo, Rodrigo, "El sistema de garantías y facilidades para el ejercicio de la función sindical. Comentarios desde un enfoque dogmático y de derecho comparado", en Palomo, Rodrigo (coord.), La organización sindical en Chile, Chile, Librotecnia, 2014, p. 375. 
Sin embargo, siendo la representación de los trabajadores el punto de partida del derecho sindical, las facilidades y garantías que se reconozcan a quienes la ejercen son cuestiones de vital relevancia en la definición de un concreto modelo de relaciones colectivas.

En esa línea, este trabajo tiene como propósitos principales explicar la naturaleza, fundamento y alcance del derecho de información de los representantes de los trabajadores, en el contexto de la democracia industrial y a la luz de las exigencias de la libertad sindical, e identificar diversas fórmulas de reconocimiento normativo de este derecho, a partir de sus elementos centrales y de las categorías jurídicas que lo definen. De ello resulta un esquema analítico que permite valorar la adecuación de un concreto sistema jurídico respecto del reconocimiento y garantía de este derecho. ${ }^{3}$

Metodológicamente, la matriz valorativa responde a un estudio eminentemente dogmático, de clarificación conceptual e identificación de categorías jurídicas, enriquecido por referencias específicas a diversos sistemas normativos que dan cuenta de la trascendencia y dinamismo del instituto analizado. Tales referencias permiten, además, contrastar un escenario normativo donde el derecho de información es un derecho de reconocimiento relativamente nuevo, de desarrollo emergente (América Latina), con otro donde está consolidado y muestra una peculiar evolución (Unión Europea), influido por la normativa comunitaria. ${ }^{4}$

3 Si bien no se pretende crear un modelo definitivo para valorar la calidad o suficiencia normativa del derecho en estudio, se sientan las bases de un modelo que facilita un análisis sistémico del mismo, aplicable respecto de distintos sistemas jurídicos. Esta perspectiva metodológica no es extraña en la ciencia jurídico-laboral. Véase, por ejemplo, García-Muñoz, Antonio et al., "Soft on the Inside, Hard on the Outside: An Analysis of the Legal Nature of New Forms of International Labour Law", International Journal of Comparative Labour Law and Industrial Relations, Holanda, 27, núm. 4, 2011, pp. 337-363. También, Álvarez del Cuvillo, Antonio, "Una aproximación metodológica al problema de la eficacia de las normas laborales”, Revista de Derecho Social, España, núm. 59, 2012, pp. 53-86.

4 Las referencias a sistemas jurídicos latinoamericanos corresponden fundamentalmente a Perú y Chile, habida cuenta de las modificaciones legales que han revitalizado el derecho de información en dichos países, en 2011 y 2016, respectivamente, en los términos que luego se comentan. Respecto del caso europeo, por su parte, las referencias corresponden fundamentalmente al sistema español, tanto por su especial desarrollo dentro del referido concierto continental, cuanto por constituir — guste o no- un indiscutible referente normativo para América Latina. Sin perjuicio de lo anterior, se incorporan también referencias específicas a otros sistemas jurídicos, en cuanto resultan pertinentes a los propósitos de este trabajo. 
Asimismo, y a modo ejemplar, se utiliza el mentado modelo analítico respecto del derecho de información reconocido a los representantes de los trabajadores en Chile, de acuerdo a la regulación aprobada por la Ley núm. 20.940, de 8 de septiembre de 2016, que moderniza el sistema de relaciones laborales.

\section{LAS BASES DOGMÁTICAS DEL DERECHO DE INFORMACIÓN DE LOS REPRESENTANTES DE LOS TRABAJADORES}

\section{La participación de los trabajadores en la empresa y el derecho de información de los representantes de los trabajadores. Distinciones iniciales}

La participación de los trabajadores es una noción elástica. Si bien lleva tiempo en el debate doctrinal, normativo y jurisprudencial en el panorama comparado, sigue representando una categoría jurídica indeterminada que admite múltiples significados. En efecto, las formas y modelos de participación de los trabajadores están condicionados por diversos factores, siendo especialmente determinantes el sistema de relaciones laborales y el modelo de representación de los trabajadores que adopta cada ordenamiento jurídico. ${ }^{5}$

Las manifestaciones de participación de los trabajadores suelen venir diferenciadas, asimismo, por la configuración de las dimensiones competencial y tutelar de los órganos titulares de dichos mecanismos, por un lado, y por la intensidad de los instrumentos participativos, por otro. ${ }^{6}$ En tal contexto, la representación colectiva de los trabajadores se erige como una forma o técnica de participación.

De otra parte, la participación de los trabajadores puede adoptar fundamentalmente tres modalidades: participación en las utilidades, participación

5 Véase a Arrigo, Gianni y Casale, Giuseppe, Una visión comparativa de los términos y conceptos de la participación de los trabajos, Documento de Trabajo núm. 8, Organización Internacional del Trabajo, Suiza, OIT, 2010, pp. 2-12. Asimismo, da buena cuenta de las discusiones actuales sobre esta materia el número monográfico presentado por Cruz, Jesús, "La participación de los trabajadores en la gestión del cambio en la empresa: entre modelos normativos y cultura de las empresas”, Documentación Laboral, España, núm. 109, 2017.

6 Baylos, Antonio, "Control obrero, democracia industrial, participación: contenidos posibles", en Aparicio, Joaquín y Baylos, Antonio, Autoridad y democracia en la empresa, España, Trotta, 1992, pp. 170 y ss. 
en la propiedad y participación en las decisiones. ${ }^{7}$ Esta última modalidad alcanza a la dimensión colectiva de las relaciones laborales, y en ella se enmarca el derecho de información objeto de este trabajo.

Por cuanto tiene relación con el grado de intensidad de los mecanismos de participación, el derecho de información de los representantes se ha concebido tradicionalmente como la fórmula participativa básica en el contexto de las relaciones industriales. Efectivamente, los tres niveles clásicos de participación en las decisiones están compuestos por el derecho de información, en el umbral mínimo, seguido por el derecho de consulta, en un nivel medio, siendo finalmente las facultades de codecisión el nivel máximo. ${ }^{8}$

La claridad de la distinción teórica se difumina, sin embargo, en su concreción práctica, donde la diferenciación entre los distintos derechos de participación de los trabajadores puede llegar a ser bien compleja, dependiendo en definitiva del concreto perfil normativo que se les otorgue. ${ }^{?}$

En efecto, desde la óptica de los representantes de los trabajadores suele hablarse de "derechos de información", incluyendo en tal expresión tanto el derecho de información propiamente tal como el derecho de consulta, esto es, el derecho a emitir una opinión frente a determinadas decisiones empresariales.

Asimismo, se distinguen tres vertientes del derecho de información propiamente tal: derecho a ser informados, derecho a informarse y derecho a informar.

$\mathrm{Al}$ derecho a ser informados se le conoce comúnmente como "derecho de información pasiva" de los representantes de los trabajadores, toda vez que bajo esta categoría se agrupan aquellos supuestos en que el empresario debe proporcionarles información, agotándose en principio el papel de los representantes con la recepción de la misma (derecho a recibir información). El derecho de información, sin embargo, no comporta una actitud completamente pasiva de los representantes de los trabajadores, toda vez que también es posible

7 Muñoz, Fernando, "Ciudadanía laboral: crítica y defensa de un concepto jurídico-político", Revista de Derecho, Chile, núm. 2, 2013, pp. 392 y ss.

8 Barbagelata, Héctor-Hugo, "Participación de los trabajadores en América Latina", Revista Derecho Laboral, Uruguay, núm. 165, 1992, p. 15.

9 Monereo identifica estos derechos con "fórmulas de participación primarias, cuya vinculación es especialmente intensa" (Monereo, José Luis, Los derechos de información de los representantes de los trabajadores, España, Civitas, 1992, p. 99). 
deducir —implícitamente de algunas competencias — un derecho a indagar o recabar otras informaciones, tanto del empresario como de otras fuentes externas a la empresa, con el objetivo de verificar o contrastar los datos facilitados o conseguir otros que se consideren necesarios para el ejercicio de determinadas competencias; es el derecho "a informarse". ${ }^{10}$ Por último, la tercera vertiente del derecho de información propiamente tal es el derecho a informar. Concretamente, se trata del derecho-deber de informar a los representados sobre el ejercicio de la acción representativa, lo cual dependerá del tipo de mandato concedido a los representantes (imperativo o representativo). ${ }^{11}$

Desde la doctrina se ha señalado que, para estos efectos, informar "es permitir el acceso a datos inherentes a la actividad y al funcionamiento de la empresa, en poder del empresario como titular de la organización, y que son naturalmente desconocidos por los trabajadores, pese a que resultan imprescindibles para el desarrollo de una actividad sindical en sentido amplio, como quiera que ésta se configure". ${ }^{12}$

Por otra parte, cabe señalar que en esta materia están extendidas las referencias legales a "derechos" y no a "competencias" de información. ${ }^{13}$ Esto ha sido criticado por un sector de la doctrina, por cuanto la voz "derecho" se asocia a la noción de derecho subjetivo, que bien se entiende dentro de un esquema jurídico en el ámbito privado, pero que sería difícilmente trasladable al ámbito de las relaciones laborales, en que encaja mejor la voz "competencias" o, con mayor precisión, "potestades jurídicas".

Encuadrada dentro del esquema de representación de los trabajadores, la información tiene una caracterización eminentemente colectiva, que conduciría a negar su conceptuación como un derecho subjetivo. En efecto, con la atribución de poderes de información a los representantes de los trabajadores el ordenamiento jurídico no está tutelando un interés propio de los mismos, cuya satisfacción pudiese depender únicamente del libre y voluntario ejercicio de un derecho — subjetivo- por aquellos. Por el contrario, se atribuye a estos

10 Monereo, José Luis, op. cit., pp. 100, 238, 393 y 394.

11 López, José, "El derecho de consulta previa como instrumento de control colectivo del poder de dirección”, Relaciones Laborales, España, núm. 19, 2005, p. 435.

12 Garrido, Eva, La información en la empresa. Análisis juridico de los poderes de información de los representantes de los trabajadores, España, Consejo Económico y Social, 1995, p. 27.

13 Así ocurre, por ejemplo, en el caso chileno (artículo 315 y siguientes del Código del Trabajo) y español (artículo 64 del Estatuto de los Trabajadores, entre otros). 
sujetos unos poderes jurídicos determinados (competencias, en sentido lato), con el propósito exclusivo de que sirvan a la función representativa, concretada en la tutela de los intereses colectivos de los trabajadores. ${ }^{14}$

Otros autores, en cambio, sostienen que sí se trata de derechos de crédito. Frente a los derechos de los representantes de los trabajadores a recibir y obtener información respecto de determinadas materias, el empresario asume la obligación de informarles. ${ }^{15}$

\section{Los fundamentos y fuentes del derecho de información de los representantes de los trabajadores}

La cuestión de la justificación jurídica del derecho de información de los representantes de los trabajadores ha ido perdiendo importancia práctica en aquellos sistemas normativos donde su reconocimiento ya está bien asentado. Tanto es así que se sostiene que en el moderno derecho del trabajo la discusión se centra en la definición de las fórmulas jurídicas que concretan aquel derecho, resultando indiscutido su fundamento. ${ }^{16}$

No siendo ese el caso predominante en los sistemas normativos de nuestro entorno, conviene mencionar que las principales tesis que se han postulado a este respecto pueden sistematizarse en torno a dos tendencias. Las que ubican la justificación de este derecho prioritariamente desde la perspectiva de los trabajadores (democracia industrial) y las que centran el enfoque en la perspectiva empresarial (función social del derecho de propiedad). ${ }^{17}$

En cualquier caso, el derecho de información de los representantes de los trabajadores está inserto en el núcleo esencial del derecho de libertad sindical,

14 Garrido, Eva, La información..., op. cit., pp. 61 y ss. Fita, por su parte, sostiene que el derecho de información es una facilidad o derecho instrumental — no una competencia en sentido estricto- que el ordenamiento jurídico reconoce a los representantes de los trabajadores en la empresa para permitirles el desempeño eficaz de sus funciones (Fita, Fernando, "El derecho de información de los representantes de los trabajadores. Diferencias según el carácter de la representación, unitaria o sindical”, Revista de Treball, España, núm. 17, 1991, p. 50).

15 Monereo, José Luis, op. cit., pp. 238 y 239.

16 Jeammaud, Antoine, "Los derechos de información y participación en la empresa: la ciudadanía en la empresa", en Aparicio, Joaquín y Baylos, Antonio, Autoridad y democracia en la empresa, España, Trotta, 1992, pp. 179 y ss.

17 Ermida, Óscar, "Participación de los trabajadores en la empresa. Panorama teórico y comparativo", Revista Derecho del Trabajo, Argentina, núm. 11, 1987, p. 1792. 
en su vertiente funcional. Efectivamente, el derecho a ejercer libremente la actividad sindical supone reconocer la facultad de utilizar los medios de acción necesarios para que el sindicato cumpla sus fines institucionales. Por tanto, los referidos representantes han de tener acceso a toda la información que sea necesaria y relevante para el ejercicio de acciones que expresen la actividad sindical, si bien ponderando la necesaria preservación de otros derechos o bienes jurídicos constitucionalmente protegidos. ${ }^{18}$

En el concierto normativo de la Organización Internacional del Trabajo (OIT), es preciso mencionar que la Recomendación 143/1971, relativa a la protección y facilidades que deben otorgarse a los representantes de los trabajadores en la empresa, establece que "los representantes de los trabajadores deberían tener la posibilidad de entrar en comunicación, sin dilación indebida, con la dirección de la empresa y con los representantes de ésta autorizados para tomar decisiones, en la medida necesaria para el desempeño eficaz de sus funciones". Esta Recomendación sirve de referente vital a la hora de precisar la interpretación y aplicación del Convenio 135/1971, de igual denominación.

Otros instrumentos de la OIT que se refieren a esta materia son los siguientes: Recomendación 94/1952, sobre la consulta y la colaboración entre empleadores y trabajadores en el ámbito de la empresa; Recomendación 129/1967, sobre las comunicaciones entre la dirección y los trabajadores dentro de la empresa; Recomendación 163/1981, referente al fomento de la negociación colectiva; y algunos Convenios, respecto de informaciones específicas, como ocurre con el Convenio 158/1982, sobre la terminación de la relación de trabajo por iniciativa del empleador.

Asimismo, el Comité de Libertad Sindical ha ratificado reiteradamente la importancia del derecho de información en la configuración de sistemas jurídicos conforme a requerimientos de libertad sindical. Así lo ha sostenido, por ejemplo, a propósito de los mecanismos destinados a facilitar la negociación colectiva y, más genéricamente, a propósito de la comunicación de sindicatos con la dirección de la empresa. ${ }^{19}$

18 En este sentido, entre otros, Sarthou, Helios, Trabajo, derecho y sociedad. Estudios de derecho colectivo del trabajo, Uruguay, Fundación de Cultura Universitaria, 2004, t. I, p. 67; Gamonal, Sergio, Derecho Colectivo del Trabajo, 2a. ed., Chile, Abeledo Perrot, 2011, p. 236; y Toledo, César, Tutela de la Libertad Sindical, Chile, Abeledo Perrot, 2013, p. 30.

19 Organización Internacional del Trabajo, La Libertad Sindical. Recopilación de decisiones y 
En cuanto a la fuente del derecho de información en los sistemas nacionales, cabe señalar que pueden ser reconocidos por la legislación (como ocurre, por ejemplo, en Perú y Chile), emanar de la autonomía colectiva (como ocurre en Uruguay), o resultar de una combinación de ambas (como en la mayoría de los sistemas de la Unión Europea). En efecto, en aquellos sistemas en que se reconoce mayor espacio a la autonomía colectiva, se entiende que el derecho de información que las normas legales otorgan a los representantes de los trabajadores opera como marco mínimo, que no puede ser renunciado, pero sí mejorado o ampliado por la negociación colectiva. Se trata de una cuestión que ha de resolverse de acuerdo a las características de cada sistema normativo y la correlación de fuentes que tiene prevista, y las peculiaridades de las concretas relaciones colectivas de trabajo.

En cualquier caso, la citada dicotomía puede llegar a revestir particular importancia, fundamentalmente por dos razones. Primero, porque la eficacia de este derecho suele verse mermada cuando su fuente es puramente heterónoma, carente de respaldo en la voluntad colectiva. Y segundo, porque si se entiende que este derecho es una limitación al poder de dirección del empleador (y se asume que éste tiene fundamento en el derecho de propiedad), sólo podría ser introducido por una ley que respete el marco constitucional. ${ }^{20}$

Ha de considerarse, además, la relevancia que puede tener la jurisprudencia (administrativa y/o judicial) como fuente del derecho de información: en su reconocimiento, en la interpretación de su régimen jurídico y en la delimitación de sus contornos. Un caso emblemático en el que la jurisprudencia ha marcado el reconocimiento de este derecho es Estados Unidos, donde fue el Consejo Nacional de Relaciones de Trabajo el que determinó que las empresas están obligadas a proporcionar información durante las negociaciones colectivas, como cuestión indesligable del deber de negociar de buena fe.21

Finalmente, respecto del ámbito europeo, debe tenerse presente que el derecho de información está contemplado en diversas normas comunitarias,

principios del Comité de Libertad Sindical del Consejo de Administración de la OIT, Suiza, 5a. versión (revisada), 2006, pp. 199 y 241.

20 Ermida, Óscar, "Participación...”, op. cit., p. 1794.

21 Boza, Guillermo, "El derecho de los trabajadores a la información en la empresa", Asesoría Laboral, Perú, núm. 8, 1991, p. 14. Un estudio interesante en esta perspectiva se presenta en Squire, Nicholas et al., Informing and Consulting Employees. The New Law, Estados Unidos, Oxford University Press, 2009. 
las que constituyen un paraguas normativo que ha permeado, de manera más o menos intensa, a la mayoría de los sistemas nacionales. ${ }^{22}$

\section{Preeminente naturaleza instrumental del derecho de información respecto del ejercicio de otras competencias representativas}

En el derecho de información se reconoce una doble naturaleza. En primer término, constituye una importante prerrogativa, identificable por sí misma dentro de cualquier marco competencial de la representación de los trabajadores en la empresa. En efecto, este derecho tiene un valor participativo propio y autónomo, en cuanto la posesión de información aumenta indudablemente el poder de quien la posee. Por consiguiente, el aumento de información en manos de los representantes de los trabajadores revaloriza su posición colectiva. ${ }^{23}$

No obstante lo anterior, destaca en la configuración jurídica del derecho de información la naturaleza instrumental que ostenta respecto del correcto desarrollo de otras competencias a las que sirve y, por elevación, respecto de la propia función representativa.

En tal sentido, las competencias tienen una dimensión institucional, puesto que definen a los órganos de representación según un determinado ámbito material de intervención, con un haz de cometidos para cuya realización se sirven de diferentes instrumentos (facultades o poderes) de acción concreta.

22 Precursor en la materia fue el Protocolo Adicional de la Carta Social Europea, de 1988, que reconoce el derecho de los representantes de los trabajadores a "ser informados periódica u oportunamente, y en manera comprensible, de la situación económica y financiera de la empresa que les da empleo, quedando entendido que podrá denegarse la divulgación de ciertas informaciones que puedan perjudicar a la empresa o exigirse que se mantengan confidenciales" (artículo 2.1.a). Dicha norma ha sido desarrollada y ampliada por diversas directivas comunitarias, generales y específicas (varias de ellas citadas en este trabajo), y por la jurisprudencia de los órganos competentes de la Unión Europea. Al respecto, véase a Cabeza, Jaime, "La doctrina del Tribunal de Justicia de la Unión Europea en materia de representación de los trabajadores", en Cabeza, Jaime y Fernández, Belén, Participación y acción sindical en la empresa, España, Bomarzo, 2013, pp. 199-215; y Navarro, Federico, Los derechos de participación de los trabajadores en el nuevo escenario del derecho del trabajo en España, España, Tirant lo Blanch, 2015.

23 Garrido afirma, en este sentido, que el derecho de información es una institución jurídica unitaria y autónoma, subrayando su continuidad a pesar de la diferencia de contextos en los que se sitúa (Garrido, Eva, La información..., op. cit., p. 298). 
La información resulta esencial para el desempeño de prácticamente todas las competencias de los representantes de los trabajadores. No obstante, su necesidad aparece más evidente ante el ejercicio de algunas en particular. Es el caso, por ejemplo, de la función de vigilancia del cumplimiento de la normativa laboral y de seguridad social que suele encomendarse a los sindicatos, respecto de la cual el derecho de información es condición básica de eficacia. Lo propio ocurre con la posición de los representantes de los trabajadores en la negociación colectiva. El derecho de información constituye un presupuesto relevante para lograr negociaciones que equilibren las expectativas del sindicato y la real situación de la empresa y el mercado. Asimismo, el derecho de información ha demostrado tener enorme virtualidad práctica en la prevención y mejor solución de conflictos colectivos. ${ }^{24}$

En razón de esta preponderante naturaleza instrumental del derecho de información, el criterio de funcionalidad es el que debería guiar, de modo transversal, su configuración jurídica e interpretación. Sólo así puede comprenderse su virtualidad operativa. Por tanto, es vital analizar el reconocimiento normativo de este derecho teniendo muy presente la configuración completa del sistema de relaciones laborales y el marco jurídico previsto para la acción colectiva.

Tal funcionalidad podrá ser genérica, respecto del ejercicio de las actividades de representación en general, o específica, si una determinada información se concibe asociada al ejercicio de una función en particular, como puede ser la información para la negociación colectiva o la información en materia de prevención de riesgos laborales. Esta distinción es relevante para determinar, por ejemplo, el carácter tasado o genérico del derecho de información de que se trate, según se comenta más adelante.

Por último, es preciso insistir en que el derecho de información es una de las denominadas "facilidades" que deben reconocerse a los representantes de los trabajadores, es decir, derechos instrumentales que han de conferírseles a fin de que puedan desarrollar adecuadamente las actuaciones que exige su función de representación. ${ }^{25}$ En tal sentido, el Convenio 135 de la OIT esta-

24 Zavala, Jaime y Vilchez, Lidia, “¿Es tan peligroso proporcionar información empresarial en el marco de la negociación colectiva? El derecho de información como mecanismo de solución de conflictos laborales”, Análisis Laboral, Perú, núm. 406, 2011, p. 16.

$25 \mathrm{Al}$ respecto, Palomo, Rodrigo, "El sistema...”, op. cit., pp. 375 y ss. 
blece que "los representantes de los trabajadores deben disponer en la empresa de las facilidades apropiadas para permitirles el desempeño rápido y eficaz de sus funciones". Se trata, pues, de un concepto jurídico indeterminado que ha de ser valorado en términos de suficiencia para el desempeño de una actividad sindical que se caracteriza por dos atributos: rápida y eficaz.

\section{LAS PRINCIPALES FÓRMULAS DE RECONOCIMIENTO NORMATIVO DEL DERECHO DE INFORMACIÓN DE LOS REPRESENTANTES DE LOS TRABAJADORES}

\section{Planteamiento}

Asentadas las bases dogmáticas del derecho de información, corresponde ahora avanzar hacia el análisis de las principales fórmulas de reconocimiento normativo de aquel.

$\mathrm{Al}$ efecto, resultan determinantes diversos elementos estructurales y las categorías jurídicas que definen a cada uno de ellos. A partir de su identificación, es posible diseñar una matriz de problematización que facilita valorar la suficiencia de una concreta fórmula jurídica de reconocimiento del derecho de información de los representantes de los trabajadores, de cara a su adecuación con los parámetros de la libertad sindical.

\begin{tabular}{|l|l|}
\hline \multicolumn{1}{|c|}{ Elementos de valoración } & \multicolumn{1}{c|}{ Categorías jurídicas que los definen } \\
\hline Alcance subjetivo & $\begin{array}{l}\text { - Sujetos destinatarios de la información. } \\
\text { - Sujetos obligados a informar. }\end{array}$ \\
\hline \multirow{3}{*}{ Alcance objetivo } & $\begin{array}{l}\text { - Fórmulas tasadas, genéricas o híbridas. } \\
\text { - Tipos de materias que deben informarse. } \\
\text { - Expresividad normativa y derechos } \\
\text { implícitos. }\end{array}$ \\
\hline Calidad de la información & $\begin{array}{l}\text { - Forma de entrega de la información. } \\
\text { - Recurso a expertos. } \\
\text { Límites del derecho de información }\end{array}$ \\
\hline & $\begin{array}{l}\text { - Periodicidad del derecho. } \\
\text { - Restricciones intrínsecas. } \\
\text { de sigilo y facultad de veto de información } \\
\text { confidencial. }\end{array}$ \\
\hline
\end{tabular}




\begin{tabular}{|l|l|}
\hline \multicolumn{1}{|c|}{ Elementos de valoración } & \multicolumn{1}{|c|}{ Categorias jurídicas que los definen } \\
\hline $\begin{array}{l}\text { Consecuencias de incumplimiento } \\
\text { empresarial }\end{array}$ & $\begin{array}{l}\text { - Régimen sancionatorio. } \\
\text { - Vías de reclamación. }\end{array}$ \\
\hline
\end{tabular}

\section{El alcance subjetivo del derecho de información}

Atendida la preeminente naturaleza instrumental con que se concibe el derecho de información, su titularidad primaria recae en los representantes de los trabajadores. Son estos los que deben desempeñar las diversas competencias que tienen asignadas a partir de la información que el empresario les facilita.

Conforme a la distinción tradicional, las competencias de los representantes de los trabajadores se agrupan en torno a las nociones de participación de los trabajadores (fundamentalmente, derechos de información y consulta, en los términos antes señalados) y representación propiamente dicha (competencias de negociación colectiva, conflicto colectivo y huelga). Esta distinción suele ser la base para la distribución de competencias entre las formas sindicales y unitarias de representación en la empresa, cuando existe doble canal, quedando reservadas, por lo general, ya sea con carácter prioritario o exclusivo, las primeras a los representantes unitarios, y las segundas a los representantes sindicales. En la actualidad, sin embargo, los contornos de esta distinción suelen ser difusos, siendo titulares del derecho de información ambas formas de representación.

En países con representación exclusiva o prioritariamente sindical, los sindicatos son los sujetos receptores de la información; es el caso, por ejemplo, de la mayoría de los sistemas latinoamericanos ${ }^{26}$. La cuestión a determinar será, entonces, qué sindicatos son titulares del derecho: todos o algunos.

Ahora bien, a falta de representación institucionalizada de los trabajadores, los ordenamientos jurídicos pueden prever que la información sea remitida a representantes elegidos especialmente a este efecto. También incide en esta cuestión el ámbito de la representación.

26 Véase un panorama general de la representación colectiva de los trabajadores en Latinoamérica en Morgado, Emilio, "La representación colectiva de los trabajadores: evolución de los regímenes legales desde la perspectiva de la autonomía colectiva y la libertad sindical", en SIDTSS, IX Congreso Regional Americano de Derecho del Trabajo y de la Seguridad Social, Ecuador, Poligráfica, 2013, pp. 61 y ss. 
Por su parte, los sistemas que reconocen representación especializada en determinadas materias (por ejemplo, en seguridad y salud laboral), definen a estos representantes como sujetos acreedores de la información en dichas materias.

Téngase presente, asimismo, que algunos contextos normativos han ido sumando otras estructuras representativas especiales, de estructura y funcionaliad compleja. Es el caso de los comités de empresa europeos, definidos como órganos colegiados y representativos que se constituyen, con arreglo a la normativa legal y comunitaria vigente, para llevar a cabo la información y consulta de los trabajadores en las empresas y grupos de empresas con dimensión comunitaria. ${ }^{27}$

Ahora, pese a que la titularidad primaria del derecho de información recae en los representantes de los trabajadores, no hay que olvidar que estos actúan representando los intereses colectivos de los trabajadores. En este sentido, y conforme al principio democrático que rige toda acción representativa, es de suma relevancia que mantengan informados a sus representados, con el objeto de completar el circuito informativo, y sirviendo de garantía del derecho de participación de los trabajadores. ${ }^{28}$

De otro lado, el sujeto obligado a proporcionar la información es, por regla general, el empleador o quien represente a la empresa. Con todo, algunos sistemas jurídicos incorporan dentro del alcance objetivo del derecho de información ciertas materias exógenas a la empresa, lo que puede dificultar el cumplimiento por el sujeto obligado a entregarla.

Así ocurre, por ejemplo, en el sistema español, donde se obliga al empresario a informar sobre la evolución general del sector económico a que pertenece la empresa. El empresario no sería el sujeto apropiado para suministrar datos genéricos sobre esta materia, pudiendo afectarse la garantía de veracidad de los mismos. En puridad, esta información debería ser facilitada por los poderes públicos. En esta lógica, el artículo 7.2.b de la Recomendación 163 de la OIT, sobre el fomento de la negociación colectiva, indica que "las autoridades públicas deberían proporcionar las informaciones necesarias sobre la situación económica y social global del país y de la rama de actividad

27 Palomo, Rodrigo, "Los comités de empresa europeos y su implantación en España. Un modelo de reconocimiento avanzado de derechos de información y consulta en empresas con dimensión comunitaria", Ius et Praxis, Chile, núm. 22, 2016, pp. 419-454.

28 Monereo, José Luis, op. cit., pp. 432 y ss. En el mismo sentido, Boza, Guillermo, El deber de sigilo de los representantes de los trabajadores, España, Tirant Lo Blanch, 1997, pp. 249 y ss. 
en cuestión, en la medida en que la difusión de tales informaciones no resulte perjudicial para los intereses nacionales".

Con todo, carece de sentido descalificar al empresario como sujeto capacitado para entregar la información referida, toda vez que no es concebible que desconozca la situación del sector en que desarrolla su actividad.

\section{El alcance objetivo del derecho de información}

Los modelos normativos se mueven entre dos fórmulas a la hora de definir las materias que deben ser informadas a los representantes de los trabajadores: establecer un catálogo tasado de supuestos sobre los que procede el deber empresarial de informar, o instituir reglas más o menos genéricas de información. Por cierto, es posible encontrar también fórmulas híbridas o eclécticas: supuestos tasados con una regla genérica de apertura o clausura, o supuestos tasados cuya descripción legal incorpora conceptos jurídicos indeterminados que dejan espacio de interpretación.

En algunos casos, por lo demás, el derecho de información se configura en términos más complejos y estrictos cuanto más compleja es la organización empresarial obligada a cumplirlo, como ocurre, por ejemplo, en Francia ${ }^{29}$ o en Chile, según se comenta más adelante.

Lo relevante es que la información que se proporcione sea suficiente para que los representantes puedan cumplir con la finalidad que justifica su otorgamiento. En este sentido, cabe adelantar que la concreta definición normativa del alcance objetivo del derecho de información admite cierta adaptabilidad, en cuanto lo exija su funcionalidad.

Doctrinalmente se han sostenido diversas clasificaciones de las materias que el empresario debería informar a los representantes. La distinción básica se plantea entre las informaciones de corte económico, aquellas de corte laboral y otras específicas.

Dentro de la información económica se distingue lo que es en sentido estricto la información financiera o societaria. Por lo respecta a la primera, suele estar referida a los resultados económicos actuales y proyectados de la

29 Lasaosa, Elena, "La representación de los trabajadores en la empresa en Francia", Revista del Ministerio de Trabajo e Inmigración, España, núm. 43, 2003, p. 101. 
empresa y, en ocasiones, también a información sobre la evolución general del sector económico a que ella pertenece, con los problemas ya advertidos.

En términos generales, esta información constituye el sustrato básico de la mayoría de las decisiones y actuaciones empresariales que dan origen a la intervención de los representantes de los trabajadores. En efecto, se trata de datos cuyo conocimiento por los representantes resulta esencial y más significativo de cara tanto al cumplimiento de su función general de defensa y promoción de los intereses colectivos de los trabajadores, como al desarrollo de sus distintas competencias específicas. ${ }^{30}$

Los ordenamientos jurídicos que reconocen, además, derechos de información financiera y societaria suelen permitir el acceso de los representantes a datos específicos y concretos de la situación productiva empresarial que sólo pueden deducirse de determinados documentos contables y societarios, normalmente a través de remisiones a la legislación mercantil.

Por su parte, la información laboral también es sumamente relevante para el correcto desarrollo de la función representativa; en especial, este derecho informativo pretende facilitar el desarrollo de la competencia más general de vigilancia del cumplimiento de las normas vigentes en materia laboral. Se compone habitualmente de información sobre contratación y subcontratación, información sobre ciertas vicisitudes contractuales (por ejemplo, información sobre determinadas modificaciones contractuales, fundamentalmente cuando tienen carácter colectivo) y sobre otras materiales laborales (por ejemplo, sanciones impuestas a los trabajadores o determinadas cuestiones relacionadas con las remuneraciones y la jornada de trabajo).

$\mathrm{Al}$ respecto, es preciso advertir que el reconocimiento del derecho de información de corte laboral debe cuidar, también, su correcta ponderación con otros derechos protegidos constitucionalmente, como puede ser el derecho a la intimidad de los trabajadores, cuyo núcleo esencial implica la existencia de un ámbito reservado frente a la acción y conocimiento de los demás. En cualquier caso, la intimidad de los trabajadores y la protección de sus datos personales podrán operar como una limitación al ejercicio del derecho de información de los representantes, mas no supone cuestionar el fundamento de tal derecho. ${ }^{31}$

30 Garrido, Eva, La información..., cit., p. 177. Destacando también la especial relevancia funcional de esta información, Monereo, José Luis, op. cit., p. 397.

31 Sobre este punto se vuelve al comentar las restricciones del derecho de información. 
Aunque no resulta fácil identificar algún dato del contrato de trabajo cuyo conocimiento por los representantes suponga transgredir el núcleo esencial del derecho a la intimidad del trabajador (al punto de hacerlo impracticable o dificultar su ejercicio más allá de lo razonable), vista la diversidad de cláusulas no resulta prudente desechar de plano que la revelación a los representantes de los trabajadores de cierta información contenida en aquel pueda llegar a suponer una intromisión a la esfera protegida por la intimidad del trabajador. ${ }^{32}$ Si llega a plantearse efectivamente la referida colisión, el interés colectivo - incluso público - debería primar, en principio, sobre el individual. ${ }^{33}$

De otra parte, se suelen contemplar también derechos informativos en materias específicas y/o emergentes (por ejemplo, crisis de la empresa, sucesión de empresas, igualdad de trato y de oportunidades entre mujeres y hombres, así como seguridad y salud en el trabajo, prevención de riesgos laborales, nuevas tecnologías). En algunos casos, el derecho de información viene previsto también en normas internacionales (OIT) o comunitarias, en el caso europeo. ${ }^{34}$

Asimismo, cabe apuntar que es común que las legislaciones reconozcan, también de forma específica, el derecho de información de los representantes de los trabajadores para efectos de la negociación colectiva. Aun cuando la configuración de este derecho concreto varía en los distintos sistemas normativos, resulta indispensable que la información que reciba el sujeto laboral que negocia sea suficiente, fidedigna y oportuna. ${ }^{35}$

32 Particularmente controvertido suele resultar el reconocimiento de un derecho de información sobre las remuneraciones, sobre todo cuando aquel alcanza a trabajadores sin afiliación sindical.

33 Sobre el impacto de la publicación de las relaciones laborales, véase a Valverde, Antonio, "Protección de datos de carácter personal y derechos de información de los representantes de los trabajadores", Temas Laborales, España, núm. 118, 2013, pp. 13 y ss. El autor concluye que debe preservarse la función de los representantes de los trabajadores, siendo necesario cohonestar los derechos en juego. En este sentido, en la medida en que se transmita información personalísima de los trabajadores a sus representantes, estos asumirían el rol de garantes de la misma en el uso que hagan de ella.

34 Es el caso, por ejemplo, de los derechos de información específicos reconocidos en la Directiva 2001/23/CE del Consejo de 12 de marzo de 2001, codificadora de la normativa comunitaria en materia de transmisión de empresa, y en la Directiva 2006/54/CE del Parlamento Europeo y del Consejo, de 5 de julio de 2006, relativa a la aplicación del principio de igualdad de trato entre hombres y mujeres en lo que se refiere al acceso al empleo, a la formación y a la promoción profesionales, y a las condiciones de trabajo.

35 En este sentido, Fontaine, Arturo. "Las comunicaciones en la negociación colectiva", 
En ocasiones, aquellos sistemas que reconocen de manera más o menos amplia el derecho de negociación colectiva ni siquiera prevén de modo expreso un derecho de información funcionalizado directamente a su desarrollo.

Así ocurre, por ejemplo, en el caso español, donde el mismo reconocimiento de la negociación colectiva como derecho trae consigo indisolublemente la exigencia de ciertas potestades informativas en favor de los sujetos negociadores. Es decir, una de las manifestaciones concretas del deber de negociar de buena fe es la obligación de suministrar información suficiente y funcional a la capacidad negociadora. El límite a la exigibilidad de información queda condicionado, pues, al ámbito material y funcional del deber de negociar, es decir, a que la información sea objetivamente relevante y necesaria para la negociación. ${ }^{36}$

Ahora bien, este repliegue normativo sólo resulta admisible cuando la consolidación del concreto sistema de relaciones colectivas, el respeto del principio de buena fe en la negociación, y el reconocimiento con carácter general de un nutrido catálogo de materias que deben informarse garantizan, de todas formas, un haz de potestades informativas en favor de los sujetos negociadores.

En el concierto latinoamericano, sin embargo, suele ser este derecho de información específico el que acapara la mayor atención del legislador, agotándose muchas veces aquí el reconocimiento de estas potestades. ${ }^{37}$

En la definición de la fórmula normativa (tasada o genérica) del ámbito objetivo incide también la funcionalidad prevista para el derecho de información de que se trate. En general, si la funcionalidad es específica, como el derecho de información para la negociación colectiva, recién comentado, se admiten fórmulas genéricas - incluso implícitas - de determinación de las materias que deben informarse: los representantes no podrán exigir más información que aquella que resulte necesaria y útil para la específica funcionalidad prevista por la norma.

en AAVV, La negociación colectiva en Chile y sus perspectivas ante las reformas laborales y los desafíos de la nueva economía, Chile, Editorial Gestión, 1997, p. 515; Franco, Julio, Marcos-Sánchez, José y Beonit, Christine, Negociación colectiva articulada. Una propuesta estratégica, Perú, Plades, 2001, p. 324.

$36 \mathrm{Al}$ respecto, véase a Garrido, Eva, La información..., op. cit., pp. 261 y ss.; y Monereo, José Luis, op. cit., pp. 119 y 395.

37 Véase Zapirain, Héctor, Derecho de información y negociación colectiva, Uruguay, Fundación de Cultura Universitaria, 2006. 
Finalmente, y según se ha adelantado, en la delimitación del alcance objetivo del derecho de información de los representantes de los trabajadores es preciso considerar también la tesis de los denominados "derechos implícitos de información". Se trata de una interpretación finalista (doctrinal y/o judicial, según los casos) que entiende que este derecho no se agotaría en aquellas materias que expresamente son reconocidas por normas legales o convencionales (criterio de la expresividad normativa), sino que su alcance llegaría a toda información necesaria para el efectivo desarrollo de la acción representativa ${ }^{38}$.

En España, por ejemplo, esta tesis ha sido resistida por la interpretación judicial mayoritaria, que hace primar el principio de expresión normativa y el carácter tasado del derecho de información. En términos generales, éste veta una posible interpretación extensiva del derecho, por cuanto su ejercicio no debería interferir más de lo necesario en lo que es competencia del empresario, ni podría superar, por ende, los límites fijados por la ley o por la autonomía colectiva, en cuanto ésta pueda ampliarlos.

La doctrina, sin embargo, ha cuestionado frontalmente la interpretación jurisprudencial, construyendo paralelamente una tesis que admite la existencia de derechos de información implícitos, siempre que resulten necesarios para el eficaz ejercicio de las competencias de representación. En esta lógica, más que a la letra de las normas — legales, reglamentarias o convencionalesque reconozcan este derecho, se debe atender a una interpretación finalista del conjunto del ordenamiento jurídico. ${ }^{39}$

En definitiva, si el derecho de información se concibe esencialmente con carácter instrumental respecto del ejercicio de las demás actuaciones de los representantes, con lo que pierde su sentido primordial desvinculado de ellas, cabe sostener, a la inversa, que aquellas tampoco pueden llevarse a cabo eficazmente sin una adecuada información que las sustente. Y el acceso a tal información no siempre estará previsto de modo expreso en el ordenamiento jurídico. El elemento que define una potestad implícita de información reside, de esta forma, en su idoneidad para hacer realmente efectivas las otras competencias que expresamente el sistema jurídico atribuya a los representantes de los trabajadores.

38 Valdés, Fernando, "Una silenciosa pero incisiva reforma: el reforzamiento de los derechos de información y consulta", Relaciones Laborales, España, vol. 1, núm. 11, 2008, p. 141.

39 Garrido, Eva, "La impronta del TJUE...", cit., pp. 365 y ss. 


\section{Algunos elementos que influyen en la calidad de la información}

Diversos elementos pueden resultar condicionantes de la calidad de la información que se entrega a los representantes de los trabajadores, incidiendo por tanto en la eficacia del derecho en estudio. Particularmente relevantes resultan la forma en que se entrega la información, la posibilidad de acceder a expertos para su comprensión y verificación, y la periodicidad con que se obliga al empresario a informar.

La forma en que se entrega la información es, entonces, uno de los factores que puede incidir de manera determinante en la calidad de la misma. La información que se da a conocer oralmente corre el riesgo de dificultar la comprobación del cumplimiento efectivo de la obligación empresarial. La información escrita, en cambio, además de facilitar su constatación, permite un estudio más detenido y pormenorizado, así como la verificación de los datos mediante su alegación documentada. Asimismo, la entrega por escrito resulta preferible atendida la complejidad del contenido de ciertas informaciones y las posibilidades de comprensión por parte de quienes las reciben. ${ }^{40}$

En esta perspectiva, la efectividad del derecho de información, en sí mismo y conectado funcionalmente con el desarrollo de las competencias que concretan la función representativa, exige también que los representantes de los trabajadores puedan comprender y asimilar los múltiples y diversos datos e informaciones que reciben. Teniendo presente que aquellos no son especialistas en todas las materias sobre las que se les puede informar, el recurso a expertos - que puedan estudiar, clarificar y verificar una determinada información - aparece como una medida instrumental idónea para alcanzar la referida efectividad. ${ }^{41}$ En algunos sistemas jurídicos, como el alemán, los servicios de estos expertos deben ser pagados por el empleador, entendiéndose que ello es garantía de la participación de los trabajadores. ${ }^{42}$

40 En este sentido, Pérez, Francisco, Derechos de información sobre empleo y contratación. Los derechos de los representantes de los trabajadores en la empresa, según la Ley 2/1991, España, Bosch, 1993 , p. 56.

41 Por todos, Vásquez, Felipe, "La información a los representantes de los trabajadores. Fines y claroscuros en su aplicación”, Relaciones Laborales, España, núm. 18, 2010, pp. 27 y ss.

42 Alzaga, Icíar, "La reforma de la Ley Alemana de Comités de Empresa", Revista del Ministerio de Trabajo e Inmigración, España, núm. 43, 2003, p. 72. 
En la misma línea, es común que las organizaciones sindicales de nivel superior (como federaciones, confederaciones y centrales sindicales) asuman entre sus funciones la asesoría técnica respecto de los sindicatos y organizaciones de base que las integran. En ejercicio de tal cometido pueden apoyar la comprensión y buen uso de la información a la que acceden los representantes de los trabajadores. ${ }^{43}$

La periodicidad con que se prevé la información a los representantes de los trabajadores es otro elemento relevante para valorar el alcance real del derecho de información en un determinado sistema jurídico. Al respecto, las legislaciones recurren a diversos criterios temporales, atendiendo fundamentalmente a la materia sobre la que debe informar el empresario. En general, debe informar cuando proceda, es decir, en el momento en que concurra alguna de las circunstancias o hechos que hacen exigible la información (así ocurre, por ejemplo, en Alemania) $)^{44}$ o en un plazo — previo o posterior- a dicha ocurrencia.

En ocasiones, sin embargo, se exige que la información se entregue con una periodicidad definida: mensual, trimestral, anual. Ahora bien, si se atiende al criterio de funcionalidad que debiese regir el reconocimiento jurídico de este derecho, debiese interpretarse que las referencias temporales que pueda establecer la norma se asocian al deber empresarial de proporcionar información, sin que supongan per se un límite al derecho de los representantes de los trabajadores a exigirla. Es decir, la periodicidad que imponga el ordenamiento jurídico a dicho derecho debería tener carácter de mínima, en cuanto obliga al empresario, pero no debiese impedir que los sujetos titulares de aquel derecho requieran información cada vez que sea necesario para el ejercicio eficaz de sus competencias. ${ }^{45}$

\section{Los límites del derecho de información}

El derecho de información, en cuanto fórmula de participación de los trabajadores en la empresa, es un instrumento encaminado a influir, con

43 Morgado, Emilio, "La representación colectiva...", cit., pp. 84 y ss.

44 Berghahn, Volker y Karsten, Detlev, Las relaciones laborales en Alemania, España, Ministerio de Trabajo y Seguridad Social, 1993, p. 123.

45 En este sentido, Cuevas, Joaquín, Estructura y función de la representación colectiva en la empresa, España, Aranzadi, 1982, p. 247. En el mismo sentido, Garrido, Eva, La información..., cit., p. 183. 
mayor o menor intensidad, en determinadas decisiones del empresario. En este sentido, su reconocimiento pone en cuestión el principio de que la dirección y gestión de la empresa se atribuye exclusivamente al empresario, al tiempo que permite el paso a la idea de democracia industrial. ${ }^{46}$

Con todo, en la configuración jurídica del derecho de información suelen incorporarse ciertos elementos normativos que permiten afirmar que aquel no implica una restricción efectiva al libre ejercicio de los poderes y libertades empresariales. Se trata de límites estructurales del derecho de información. Por ejemplo, el carácter tasado de los derechos informativos y el carácter no vinculante de las opiniones de los representantes dan pie para concluir que en su definición normativa ha primado la protección de los intereses empresariales frente a las exigencias reales de una eficiente labor representativa de los intereses de los trabajadores. Así, para el empresario se presenta más como un factor o presupuesto legitimador de sus decisiones, de cara a los trabajadores, que como una restricción real de su espacio de actuación. ${ }^{47}$

En la ponderación de los intereses empresariales y laborales, por tanto, resultan determinantes las expresiones institucionales de alcance e intensidad jurídica variable, con que se reconozca el derecho de información y, por cierto, la interpretación judicial que se haga de las mismas.

A dichas restricciones estructurales o intrínsecas han de añadirse las limitantes que pueden imponerse al ejercicio del derecho de información; principalmente, el deber de sigilo y la facultad de veto empresarial. ${ }^{48}$

El deber de sigilo constituye, en esencia, el reverso del derecho de información de los representantes de los trabajadores. Por esta vía, según se ha venido comentando, los representantes de los trabajadores pueden llegar a acceder a importante y diversa información empresarial y laboral, por lo que los ordenamientos jurídicos procuran proveer los mecanismos para evitar su uso desviado o abusivo, entre ellos, la exigencia de un uso prudente de la información, de acuerdo a los fines para los cuales fue entregada.

$46 \mathrm{Al}$ respecto, Monereo, José Luis, op. cit., pp. 82 y ss. Una visión crítica en Hayek, Friedrich, Sindicatos, ¿̇para qué?, España, Unión Editorial, 2009.

47 Garrido, Eva, La información..., cit., pp. 89 y 90.

48 Sobre esta distinción, revísese Boza, Guillermo, "Los límites del derecho de información: una sistematización de la normativa internacional, comunitaria y de derecho comparado", Revista Themis, Perú, núm. 34, 1997, pp. 67-87. 
En este sentido, lo que tipifica a la obligación de sigilo que suele exigirse a los representantes de los trabajadores es precisamente que el empleador deba facilitarles, en los términos y con la intensidad que se establezca en cada ordenamiento, la información que luego constituye el contenido material de aquel deber. Si bien el deber de sigilo no se corresponde correlativamente con ningún derecho concreto del empresario, no es menos cierto que el fundamento último de la imposición de este deber responde, por lo general, a la protección de ciertos intereses empresariales (la imagen corporativa, la intimidad empresarial o la actuación del empresario en una economía competitiva). ${ }^{49}$

Los problemas que puede plantear la definición concreta de este deber de sigilo también son múltiples y diversos: quiénes son los sujetos obligados (tráigase a la vista lo dicho respecto del derecho-deber de informar a los representados), cuál es su contenido material, cuál es su extensión temporal, cuáles son las consecuencias jurídicas de su vulneración (asociadas, en principio, al interés jurídico que se pretende proteger con el carácter reservado o secreto de determinada información),,$^{50}$ entre otros.

Particular interés despierta la delimitación del contenido material de la obligación de sigilo. Cabe sentar la premisa básica de que aquel no cubre, por naturaleza, toda la extensión material del derecho de información que se reconozca a los representantes de los trabajadores. ${ }^{51}$ Por el contrario, si se respeta el criterio de funcionalidad, sólo cabría imponer este límite a la información que efectivamente tenga carácter reservado. Por la misma razón, tal calificación no debería quedar al arbitrio del empresario, toda vez que ello podría significar poner en jaque la eficacia real del derecho de información, al punto de dejarlo en riesgo de verse inoperativo frente a su rol instrumental. Llegados a este punto, cabe concluir que el carácter reservado con que se comunican determinadas informaciones, que justifica consecuencialmen-

49 Fernández, María Fernanda, "El deber de sigilo de los representantes del personal", Actualidad Laboral, España, núm. 9, 1992, p. 134; Boza, Guillermo, El deber de sigilo..., cit., p. 190.

50 Los ordenamientos jurídicos prevén diversas sanciones para tal supuesto: disciplinarias, civiles e incluso penales. Lo relevante es que las sanciones no lleguen a anular el ejercicio del derecho de información, atendida su naturaleza colectiva, y que tengan relación equitativa con las sanciones que se contemplen por incumplimiento empresarial de la obligación de informar.

51 No resultaría ajustado a derecho convertir un límite, como es el deber de sigilo, en regla general. Por lo mismo, cualquier ponderación de este deber con otros derechos habría de partir del entendimiento de que aquel es una excepción al derecho de información de los representantes de los trabajadores, cuyo alcance, por tanto, exige una interpretación restrictiva. 
te un deber de sigilo, debe obedecer a un legítimo y objetivo interés laboral o empresarial. 52

Siguiendo los mismos criterios de objetividad, los sistemas jurídicos pueden prever excepcionalmente materias respecto de las cuales la empresa no está obligada a informar. A diferencia de la información reservada, que pertenece al ámbito habitual de las relaciones colectivas, la información confidencial está referida a datos que, o están protegidos por la legislación de propiedad industrial o intelectual, o han sido declarados expresamente secretos por la empresa, por existir un interés concreto y objetivo digno de esta mayor protección. Se trata, entonces, de la posibilidad de bloquear la transmisión de cierta información que es considerada confidencial por el empresario.

La amplitud con que se concibe este derecho de veto empresarial incide también en la funcionalidad del derecho de información de los representantes de los trabajadores. En particular, la indeterminación del alcance de la facultad en cuestión y la ausencia o insuficiencia de los mecanismos de control de la objetividad de la calificación empresarial, podrían vaciar de contenido el derecho de información.

\section{Las consecuencias del incumplimiento empresarial del derecho de información}

La principal dificultad para la eficacia del derecho de información de los representantes de los trabajadores suele venir dada por la determinación de las sanciones frente al incumplimiento de los deberes correlativos del empresario.

Es claro que la vulneración del derecho de información importa la configuración de una infracción laboral, por lo que cada sistema jurídico ha de precisar las consecuencias de la misma. Dicha determinación podrá depender de diversos factores, como el contenido específico del derecho de información incumplido o la gravedad o trascendencia del incumplimiento.

52 García, Elena y Mira, Javier, "Deber de sigilo de los representantes de los trabajadores y derechos fundamentales: libertad sindical y libertades de expresión e información: algunos puntos críticos", en AA.VV., Presente y futuro de la Constitución española de 1978, Valencia, Tirant Lo Blanch, 2005, p. 334; López, José, "Ejercicio de los derechos de información y expresión en caso de huelga: ¿posible aplicación del deber de sigilo profesional?”, Aranzadi Social, Estudios Doctrinales, Madrid, núm. 3, 2006, p. 3021. 
Así pues, las sanciones podrán ir desde la sola aplicación de una multa administrativa hasta la afectación de la validez o procedencia de los actos empresariales que han debido informarse o de los supuestos jurídicos que se ven determinados por la ausencia de la información requerida.

Revísese, a modo ejemplar, el caso peruano. El incumplimiento del derecho de información de los sindicatos previsto para la negociación colectiva originalmente sólo generaba una sanción económica para el empresario, la que no era disuasiva. ${ }^{53}$ En 2011, sin embargo, la Decreto Supremo núm. 0142011-TR incluyó este incumplimiento como causal de arbitraje potestativo, lo que se ha traducido en un cambio de comportamiento significativo respecto del derecho de información en la negociación colectiva, que ahora tiene una tasa mucho mayor de cumplimiento. ${ }^{54}$

En definitiva, por muy amplia que sea la extensión objetiva del derecho de información, su eficacia será limitada si aparece débil en intensidad, en cuanto queda relegada a la periferia del poder decisional del empresario. ${ }^{55}$

Así las cosas, la definición de las sanciones por incumplimiento de estos derechos revitaliza su carácter instrumental, dado que su principal relevancia se evidencia en cuanto sirven al eficaz ejercicio de otras competencias de los representantes de los trabajadores.

$\mathrm{Al}$ alero de la referida funcionalidad, alguna jurisprudencia ha incorporado el criterio de la trascendencia del incumplimiento del derecho de información, para determinar el régimen sancionatorio, máxime cuando la sanción consiste en la nulidad de un acto empresarial. De acuerdo a esta tesis, no cualquier incumplimiento ha de determinar dicha sanción para el empresario, ya que tal consecuencia sólo debería producirse cuando el incumplimiento del derecho de información sea trascendente a los efectos de la funcionalidad esperada del mismo. ${ }^{56}$

$53 \mathrm{Al}$ respecto, Villavicencio sostiene que "cuando se monetariza el incumplimiento de un derecho fundamental, el sujeto que está en condiciones de pagar, pues paga" (Villavicencio, Alfredo, "Luces y sombras del arbitraje en la negociación colectiva", en AAVV, VI Congreso Nacional de Derecho del Trabajo y de la Seguridad Social, Perú, Sociedad Peruana de Derecho del Trabajo y de la Seguridad Social, 2014, pp. 888.

54 Boza, Guillermo, "El derecho de información de los representantes de los trabajadores en el ordenamiento laboral peruano", en Palomo, Rodrigo (dir.), Derecho de información de los sindicatos, Chile, Librotecnia, 2017, pp. 201 y ss.

55 Sáez, Carmen, Representación y acción sindical en la empresa, España, Ministerio de Trabajo y Seguridad Social, 1992, p. 87.

56 Desde una perspectiva crítica, véase Garrido, Eva, "La impronta del TJUE...", cit., p. 377. 
Por cuanto dice relación con las vías para reclamar el incumplimiento del derecho de información, las normas frecuentan contemplar acciones administrativas y judiciales. Estas últimas podrán tramitarse de acuerdo al procedimiento general, al procedimiento de tutela de derechos fundamentales, o al procedimiento de conflicto colectivo, pudiendo resultar relevante esta cuestión en atención a las garantías procesales que se prevean en cada sistema. Téngase presente, finalmente, que en algunos ordenamientos se contempla la posibilidad de someter estos incumplimientos a mecanismos alternativos de solución de conflictos, como mediaciones y arbitrajes. Además, ha de considerarse la garantía de indemnidad por ejercicio del derecho de información.

\section{EL DERECHO DE INFORMACIÓN DE LOS REPRESENTANTES DE LOS TRABAJADORES EN CHILE}

\section{Planteamiento y contexto normativo del reconocimiento del derecho de información en el ordenamiento jurídico chileno}

Explicada la naturaleza, fundamento y alcance del derecho de información de los representantes de los trabajadores, en el contexto de la democracia industrial y a la luz de las exigencias de la libertad sindical, e identificadas las principales fórmulas de reconocimiento normativo de este derecho, a partir de sus elementos centrales y de las categorías jurídicas que lo definen, se expone en seguida la aplicación de dicho modelo analítico respecto del derecho de información en Chile. No se pretende, según se ha dicho, analizar con detención la regulación normativa del referido país, sino demostrar la pertinencia de la referida matriz de problematización, de cara a valorar un concreto sistema jurídico sobre el reconocimiento, garantía y funcionalidad de esta derecho. ${ }^{57}$

Pues bien, el actual modelo normativo sobre relaciones colectivas en Chile, impuesto originalmente por el denominado "Plan Laboral" de la dictadura militar, limita fuertemente la vigencia de los derechos que integran la libertad sindical. Si bien este sistema normativo ha sido objeto de varias reformas tras

57 Para un detenido análisis del derecho de información de los sindicatos en Chile, véase Palomo, Rodrigo, "El nuevo derecho de información de los sindicatos. Un ejemplo de reforma en la periferia del modelo", en Arellano, Pablo et al., Reforma al derecho colectivo del trabajo. Examen crítico de la Ley núm. 20.940, Chile, Thomson Reuters, 2016, pp. 109-133. 
el retorno de la democracia, éstas no han afectado su esencia, aun cuando han incidido, con distinta intensidad, en la regulación de las relaciones colectivas de trabajo. 58

En este contexto, el reconocimiento del derecho de información de los representantes de los trabajadores es de reciente data en Chile. El principal referente normativo de este derecho fue incorporado por la denominada "segunda reforma laboral" de los gobiernos de la Concertación, anclado a la regulación del procedimiento de negociación colectiva reglada de empresa. Con anterioridad a dicha reforma, las manifestaciones normativas de este derecho fueron marginales..$^{59}$

En efecto, la Ley núm. 19.759, de 2001, reconoció por primera vez de manera explícita el derecho de información, reconduciéndolo fundamentalmente a la norma que estuvo contenida en los incisos 5 y 6 del artículo 315 del Código del Trabajo.

Conforme a dicha norma, todo sindicato o grupo negociador podía solicitar del empleador, dentro de los plazos que indicaba, los antecedentes indispensables para preparar el proyecto de contrato colectivo. Enseguida agregaba que el empleador estaba obligado a entregar, a lo menos, los dos últimos balances anuales, salvo que la empresa tuviere una existencia menor, la información financiera necesaria para la confección del proyecto referida a los meses del año en ejercicio, y los costos globales de mano de obra del mismo periodo. Asimismo, debía entregar la información pertinente que incidiera en la política futura de inversiones de la empresa, siempre que no la considerara confidencial.

Es evidente que dicha norma estaba llena de conceptos jurídicos indeterminados, que en la práctica condujeron a que el derecho de información en la negociación colectiva fuese casi una ilusión jurídica.

La negativa del empleador a suministrar la información necesaria para la justificación de sus argumentaciones constituía una práctica desleal en la ne-

58 Para una visión panorámica de la situación normativa actual de la libertad sindical en Chile, véase Rojas, Irene y Tapia, Francisco, "Las relaciones laborales colectiva en Chile", en Mangarelli, Cristina et al., (coords.), Las relaciones laborales colectivas en América Latina y España, España, Tirant Lo Blanch, 2015, pp. 135-173.

59 Sobre los hitos histórico-normativos del derecho de información de los sindicatos en Chile, véase González, Daniela, "Antecedentes históricos del derecho de información en la negociación colectiva", en Palomo, Rodrigo (dir.), Derecho de información de los sindicatos, Chile, Librotecnia, 2017, pp. 53-82. 
gociación colectiva. Del mismo modo, la divulgación por directores sindicales, a terceros ajenos al sindicato, de documentos o información confidencial o reservada recibida del empleador constituía una práctica antisindical.

Poco más se encontraba fuera del derecho de información previsto a propósito de la negociación colectiva reglada.$^{60} \mathrm{El}$ legislador parecía entender, de este modo, que el sindicato sólo precisaba alguna información para preparar la negociación colectiva, debiendo ejercer todas sus demás funciones a ciegas o, en el mejor de los casos, apelando a la buena voluntad empresarial.

Tal reconocimiento del derecho de información de los representantes de los trabajadores en la negociación colectiva era insuficiente, tanto en su propia configuración jurídica como, por cierto, en el contexto del reconocimiento general del derecho de información de los sindicatos. ${ }^{61}$ Era necesario, claro está, reformular las bases para el efectivo reconocimiento normativo del derecho de información de los sindicatos, ampliando sustancialmente su alcance objetivo, y mejorando la calidad de la información y sus garantías.

\section{El nuevo derecho de información regulado en la Ley núm. 20.940}

El actual régimen jurídico del derecho de información de los representantes de los trabajadores en Chile viene determinado por la Ley núm. 20.940, sobre modernización de las relaciones laborales, vigente desde abril de 2017. Esta reforma laboral ha supuesto nuevamente ajustes dentro de la lógica del modelo imperante, limitando ab initio el alcance cualitativo y cuantitativo de las medidas proyectadas. ${ }^{62}$

60 Destaca, con todo, la obligación de informar sobre riesgos laborales regulada principalmente en el Decreto Supremo núm. 40/1969, que aprueba el Reglamento sobre Prevención de Riesgos Profesionales. Asimismo, ha de mencionarse la obligación empresarial de entregar copia a los sindicatos de los reglamentos internos y sus modificaciones, conforme prescribe el artículo 156 del Código del Trabajo.

61 En razón de lo dicho, se sostenía que tal regulación era "escasa, fragmentaria, dispersa e inorgánica sobre el reconocimiento, ejercicio y límites del derecho de información” (Domínguez, Álvaro, "Presente y futuro del derecho de información de las organizaciones sindicales en Chile", en AA.VV., XXII Jornadas Nacionales de la Sociedad Chilena de Derecho del Trabajo y de la Seguridad Social. Análisis crítico de la reforma al sistema de relaciones sindicales en Chile, Chile, Universidad de Chile, 2015, p. 80.

62 Un análisis valorativo de la reforma laboral chilena, operada por la Ley núm. 20.940, en Palomo, Rodrigo, "Expectativa vs. realidad en la reforma laboral chilena. El nuevo derecho de 
En esta perspectiva, los artículos 315 a 319 del Código del Trabajo establecen una nueva regulación del derecho referido, en la que ha sido la modificación más intensa a dicho instituto desde su reconocimiento en 2001. En efecto, la nueva regulación supone un avance respecto de la anterior, ${ }^{63}$ pero se queda a medio camino, tanto por el alcance general de la última reforma laboral como por su incidencia en la delimitación de los contornos normativos del derecho de información, en particular. ${ }^{64}$

Para probar lo dicho, bien vale someter esta nueva regulación a la matriz analítica presentada en la primera parte de este trabajo.

La primera dimensión que condiciona la eficacia del derecho de información en Chile es su alcance subjetivo. La ley establece que los sindicatos - $\mathrm{y}$ particularmente, los sindicatos de empresa o aquellos que tienen derecho a negociar colectivamente, según los casos - son los titulares exclusivos del derecho de información. ${ }^{65}$ Considerando que en el citado país tan sólo nueve de cada cien empresas cuentan con al menos un sindicato de empresa o establecimiento activo, y que no se contemplan otros mecanismos de representación o participación de los trabajadores en empresas sin sindicatos, la virtualidad

información de los sindicatos como paradigma de una reforma transaccional", Derecho Laboral, Uruguay, núm. 263, 2016, pp. 475-492.

63 En este sentido, la Comisión de Expertos en Aplicación de Convenios y Recomendaciones de la OIT observa "con satisfacción" la ampliación del derecho de información por la Ley núm. 20.940 (Organización Internacional del Trabajo, Informe de la Comisión de Expertos en Aplicación de Convenios y Recomendaciones, Informe III, Parte 1 A, Suiza, OIT, 2017, p. 87).

64 Atendida la preeminente naturaleza instrumental del derecho de información, de poco sirve robustecerlo si el contexto normativo en que está llamado a servir no sigue igual suerte. En esta línea, desde una perspectiva más general sobre la eficacia de las normas laborales, Álvarez del Cuvillo, Antonio, op. cit., p. 68.

Dicho de otro modo, y respecto del caso chileno, la posibilidad de aumentar la virtualidad práctica del derecho de información de los sindicatos es baja si no se modifican sustancialmente los institutos jurídicos que son determinantes de la baja afiliación sindical, de la escasa incidencia de la negociación colectiva en el sistema de relaciones laborales, y del constreñido espacio reconocido al conflicto colectivo. Tal modificación no se ha producido por la Ley referida.

65 La excepción a este respecto es el derecho de información específico para la negociación colectiva, reconocido también al grupo negociador. Téngase presente que en el sistema normativo chileno tienen titularidad negocial por los trabajadores tanto los sindicatos como grupos transitorios de trabajadores que se reúnan con el sólo propósito de negociar colectivamente. Véase una aproximación crítica a esta definición normativa en Severín, Juan Pablo, "Los sujetos de la negociación colectiva y la titularidad sindical", en Arellano, Pablo et al., Reforma al derecho colectivo del trabajo. Examen crítico de la Ley núm. 20.940, Chile, Thomson Reuters, 2016, pp. 87-107. 
práctica del derecho en estudio se resiente fuertemente. ${ }^{66}$ En efecto, la legislación chilena no contempla, como sí ocurre en otros sistemas normativos, fórmulas ad hoc para canalizar información en empresas sin sindicato, como podrían ser las representaciones electas o unitarias.

El segundo elemento de valoración está en relación con el alcance objetivo del derecho de información. Al respecto, la nueva regulación legal distingue entre el derecho de información periódica, el derecho de información específica para la negociación colectiva, y el derecho de información por cargos o funciones de los trabajadores. Las materias que deben informarse en cada caso han quedado determinadas por el tamaño de la empresa.

En concreto, el contenido del derecho de información periódica está referido exclusivamente a información económica y financiera de la empresa (artículos 315 y 318 del Código del Trabajo). Para la negociación colectiva, por su parte, el derecho de información cubre la planilla de remuneraciones de los afiliados al sindicato, el valor actualizado de los beneficios del instrumento colectivo vigente, los costos globales de mano de obra de la empresa, la información periódica que no haya sido otorgada oportunamente, y la información que incida en la política futura de inversiones de la empresa (artículo 316 del Código del Trabajo). El derecho de información por cargos o funciones de los trabajadores, por último, habilita a los sindicatos para acceder a información innominada sobre remuneraciones asignadas a trabajadores de los diversos cargos o funciones de la empresa, en los términos que establece la ley (artículo 317 del Código del Trabajo). ${ }^{67}$

Como puede apreciarse, la ley ha dejado fuera, nuevamente, informaciones de corte laboral (por ejemplo, sobre contratación y subcontratación, o sobre ciertas vicisitudes contractuales) y otras específicas que suelen contenerse en

$66 \mathrm{Al}$ respecto, Departamento de Estudios de la Dirección del Trabajo, Informe de resultados. Octava Encuesta Laboral (Encla), Chile, Dirección del Trabajo, 2014, pp. 157 y ss.

67 El derecho de información remuneracional — tanto el contemplado para la negociación colectiva como el referido a cargos y funciones- fue objeto de un requerimiento de inconstitucionalidad durante la tramitación parlamentaria de la Ley núm. 20.940, arguyéndose que su reconocimiento vulneraría el derecho a la privacidad de los trabajadores. El Tribunal Constitucional rechazó dicha objeción, primero, porque la información en cuestión no es ajena al sindicato, sino que, por el contrario, se otorga en el marco de sus roles propios. Además, cuenta con resguardos justos y necesarios para compatibilizar, por una parte, la entrega de información, con la publicidad que pueda darse respecto de la remuneración de los trabajadores (Sentencia del Tribunal Constitucional, Rol núm. 3016/3026, de 9 de mayo de 2016). 
legislaciones de otros países con sistemas laborales más avanzados. En efecto, urge el reconocimiento legal de otros derechos de información específicos, por ejemplo, en supuestos de transmisión de empresas, donde la información es esencial para la identificación de los titulares de las mismas y la efectividad del ejercicio de los derechos laborales. ${ }^{68}$

Además, la normativa reformada ha optado por un modelo eminentemente tasado respecto de las manifestaciones del derecho de información que no tienen una funcionalidad explícita y directa (derecho de información periódica y derecho de información por cargos o funciones de los trabajadores). Descarta, de este modo, incorporar una regla más o menos genérica de información, que permita cierta laxitud respecto de supuestos no previstos por el legislador y que sirva de insumo relevante de interpretación en casos complejos. Distinto es el criterio legal cuando se trata del derecho de información específica para la negociación colectiva, donde precisamente esa explícita funcionalidad sirve de límite al alcance objetivo del derecho, dejando espacio a una cláusula genérica de entrada.

Más allá del reconocimiento legal, no puede sostenerse que el derecho de información vaya a mejorar cualitativa y cuantitativamente por vía de la autonomía colectiva, atendido el limitado contenido de los instrumentos colectivos en Chile, por definición legal e interpretación jurisprudencial, y la exigua realidad de la negociación colectiva en ese país. ${ }^{69}$

En cuanto a los elementos que inciden en la calidad de la información, la nueva regulación plantea algunos avances, entre los que es preciso mencionar la periodicidad anual establecida respecto del derecho de información periódica y el derecho de información por cargos y funciones de los trabajadores. Asimismo, el nuevo marco jurídico determina con claridad los plazos de entrega de información.

Sin embargo, se mantienen otros factores que pueden incidir negativamente en el derecho de información. Así, por ejemplo, no se dan garantías

68 Véase Jofré, María Soledad y Planet, Lucía, "Derecho de información en supuestos de cambios empresariales por transmisión o por crisis de la empresa en Chile", en Palomo, Rodrigo (dir.), Derecho de información de los sindicatos, Chile, Librotecnia, 2017, pp. 84-103.

69 Caamaño, Eduardo, "Las materias objeto de negociación colectiva y la libertad sindical: el fantasma de los 'Chicago Boys' a 30 años del Plan Laboral”, en Caamaño, Eduardo y Pereira, Rafael (dir.), Estudios de derecho del trabajo y de la seguridad social, Chile, Abeledo Perrot, 2012, vol. IV, pp. 201 y ss. 
suficientes del carácter fidedigno de la información que se entrega a los representantes, ni se regula la forma de transmisión de la información. ${ }^{70}$ Tampoco se facilita en todos los casos el acceso a expertos a efecto de favorecer la comprensión de informaciones técnicas o complejas, salvo en procesos de negociación colectiva. ${ }^{71}$

En lo referente a las restricciones al ejercicio del derecho, se consagra muy rudimentariamente el deber de sigilo. Se considera una práctica antisindical de los trabajadores divulgar a terceros ajenos al sindicato (o a la negociación, en su caso) los documentos o la información que hayan recibido del empleador y que tengan el carácter de confidencial o reservados.

Por otra parte, el empresario mantiene su facultad de calificar cierta información (aquella que incida en la política futura de inversiones de la empresa) como confidencial, sin que pueda verificarse que dicha decisión obedezca a criterios objetivos.

Con todo, la principal dificultad para la eficacia del derecho de información de los sindicatos viene dada por las sanciones que se prevén frente al incumplimiento del deber correlativo del empresario. Si bien la norma contempla la posibilidad requerir información por vía administrativa y judicial, la negativa a proporcionar la información contemplada en la ley sólo configura una práctica antisindical, cuyos efectos no siempre serán lo suficientemente disuasivos del incumplimiento. En efecto, la infracción de este derecho no afecta la validez o procedencia de los actos empresariales que se informan.

Pese a que se ha constatado que la falta de entrega de información es una infracción empresarial recurrente, puede proyectarse que se mantendrá la escasa conflictividad a su respecto, vista la escasa virtualidad práctica que de ella deriva.

70 Atendiendo a un criterio finalista y de eficacia, se postula que "la transmisión de la información debe necesariamente materializarse en un soporte que permita su estudio y consulta, siendo únicamente posible que su entrega sea en forma escrita" (Domínguez, Álvaro, op. cit., p. 93).

71 El artículo 343 del Código del Trabajo consagra el derecho de las partes a solicitar una reunión de asistencia técnica, como un mecanismo orientado a facilitar el desarrollo de la negociación en micro y pequeñas empresas ( $\mathrm{y}$ en empresas medianas que negocien por primera vez), informando a las partes sobre aspectos técnicos de la misma (procedimiento, plazos, derechos y obligaciones). Asimismo, tanto el empleador como el sindicato pueden designar hasta tres asesores que les asistan en el desarrollo de las negociaciones. 
En definitiva, los avances que plantea la última reforma laboral son parciales, están en la periferia del instituto analizado, y su operatividad depende en buena medida de elementos normativos que no han sido alterados sustancialmente.

\section{BIBLIOGRAFÍA}

Álvarez del Cuvillo, Antonio, "Una aproximación metodológica al problema de la eficacia de las normas laborales", Revista de Derecho Social, España, núm. 59, 2012.

AlZAGA, Icíar, "La reforma de la Ley Alemana de Comités de Empresa", Revista del Ministerio de Trabajo e Inmigración, España, núm. 43, 2003.

ARrigo, Gianni y CASALE, Giuseppe, Una visión comparativa de los términos y conceptos de la participación de los trabajos, Organización Internacional del Trabajo, Suiza, 2010, Documento de Trabajo núm. 8.

Barbagelata, Héctor-Hugo, "Participación de los trabajadores en América Latina”, Revista Derecho Laboral, Uruguay, núm. 165, 1992.

BAYLOS, Antonio, "Control obrero, democracia industrial, participación: contenidos posibles", en APARICIO, Joaquín y BAYLOS, Antonio, Autoridad y democracia en la empresa, España, Trotta, 1992.

Berghahn, Volker y KARSten, Detlev, Las relaciones laborales en Alemania, España, Ministerio de Trabajo y Seguridad Social, 1993.

BOZA, Guillermo, El deber de sigilo de los representantes de los trabajadores, España, Tirant Lo Blanch, 1997.

BOZA, Guillermo, "El derecho de información de los representantes de los trabajadores en el ordenamiento laboral peruano", en PALOMO, Rodrigo (dir.), Derecho de información de los sindicatos, Chile, Librotecnia, 2017.

BOZA, Guillermo, "El derecho de los trabajadores a la información en la empresa”, Asesoría Laboral, Perú, núm. 8, 1991.

BOZA, Guillermo, "Los límites del derecho de información: una sistematización de la normativa internacional, comunitaria y de derecho comparado", Revista Themis, Perú, núm. 34, 1997. 
CAAMAÑO, Eduardo, "Las materias objeto de negociación colectiva y la libertad sindical: el fantasma de los 'Chicago Boys' a 30 años del Plan Laboral”, en CAAmaÑo, Eduardo y PEREIRA, Rafael (dir.), Estudios de Derecho del Trabajo y de la Seguridad Social, Chile, Abeledo Perrot, vol. IV, 2012.

CABEZA, Jaime, "La doctrina del Tribunal de Justicia de la Unión Europea en materia de representación de los trabajadores", en CABEZA, Jaime y FERNÁNDEZ, Belén, Participación y acción sindical en la empresa, España, Bomarzo, 2013.

CRUZ, Jesús (coord.), "La participación de los trabajadores en la gestión del cambio en la empresa: entre modelos normativos y cultura de las empresas”, Documentación Laboral, España, núm. 109, 2017.

CUEVAS, Joaquín, Estructura y función de la representación colectiva en la empresa, España, Aranzadi, 1982.

Departamento de Estudios de la Dirección del Trabajo, Informe de resultados. Octava Encuesta Laboral (Encla), Chile, Dirección del Trabajo, 2014.

Domínguez, Álvaro, "Presente y futuro del derecho de información de las organizaciones sindicales en Chile", en AA.VV., XXII Jornadas Nacionales de la Sociedad Chilena de Derecho del Trabajo y de la Seguridad Social. Análisis crítico de la reforma al sistema de relaciones sindicales en Chile, Chile, Universidad de Chile, 2015.

ERMIDA, Óscar, "Participación de los trabajadores en la empresa. Panorama teórico y comparativo", Revista Derecho del Trabajo, Argentina, núm. 11, 1987.

FERNÁNDEZ, María Fernanda, "El deber de sigilo de los representantes del personal”, Actualidad Laboral, España, núm. 9, 1992.

FITA, Fernando, "El derecho de información de los representantes de los trabajadores. Diferencias según el carácter de la representación, unitaria o sindical", Revista de Treball, España, núm. 17, 1991.

FONTAINE, Arturo, "Las comunicaciones en la negociación colectiva", en AA.VV., La negociación colectiva en Chile y sus perspectivas ante las reformas laborales y los desafios de la nueva economía, Chile, Editorial Gestión, 1997.

FrANCO, Julio et al., Negociación colectiva articulada. Una propuesta estratégica, Perú, Plades, 2001. 
Gamonal, Sergio, Derecho colectivo del trabajo, 2a. ed., Chile, Abeledo Perrot, 2011.

GARCÍA, Elena y MiRA, Javier, "Deber de sigilo de los representantes de los trabajadores y derechos fundamentales: libertad sindical y libertades de expresión e información: algunos puntos críticos", en AA.VV., Presente y futuro de la Constitución española de 1978, Valencia, Tirant Lo Blanch, 2005.

GARCÍA-MuÑOZ, Antonio et al., "Soft on the Inside, Hard on the Outside: An Analysis of the Legal Nature of New Forms of International Labour Law", International Journal of Comparative Labour Law and Industrial Relations, Holanda, vol. 27, núm. 4, 2011.

GARRIDO, Eva, "La impronta del TJUE en el tratamiento español de los derechos de información y consulta, en especial en despidos colectivos", Temas Laborales, España, núm. 130, 2015.

GARRIDO, Eva, La información en la empresa. Análisis jurídico de los poderes de información de los representantes de los trabajadores, España, Consejo Económico y Social, 1995.

GONZÁLEZ, Daniela, “Antecedentes históricos del derecho de información en la negociación colectiva", en PALOMO, Rodrigo (dir.), Derecho de información de los sindicatos, Chile, Librotecnia, 2017.

HAYEK, Friedrich, Sindicatos, ¿̇para qué?, España, Unión Editorial, 2009.

JEAmMAUD, Jeammaud, Antoine, "Los derechos de información y participación en la empresa: la ciudadanía en la empresa”, en APARICIO, Joaquín y BAYlos, Antonio, Autoridady democracia en la empresa, España, Trotta, 1992.

Jofré, María Soledad y PlANET, Lucía, "Derecho de información en supuestos de cambios empresariales por transmisión o por crisis de la empresa en Chile", en PALOMO, Rodrigo (dir.), Derecho de información de los sindicatos, Chile, Librotecnia, 2017.

LASAOSA, Elena, "La representación de los trabajadores en la empresa en Francia", Revista del Ministerio de Trabajo e Inmigración, España, núm. 43, 2003.

LÓPEZ, José, "Ejercicio de los derechos de información y expresión en caso de huelga: ¿posible aplicación del deber de sigilo profesional?”, Aranzadi Social, Estudios Doctrinales, Madrid, núm. 3, 2006. 
LÓPEZ, José, "El derecho de consulta previa como instrumento de control colectivo del poder de dirección", Relaciones Laborales, España, núm. 19, 2005.

MonereO, José Luis, Los derechos de información de los representantes de los trabajadores, España, Civitas, 1992.

Morgado, Emilio, "La representación colectiva de los trabajadores: evolución de los regímenes legales desde la perspectiva de la autonomía colectiva y la libertad sindical", en SIDTSS, IX Congreso Regional Americano de Derecho del Trabajo y de la Seguridad Social, Ecuador, Poligráfica, 2013.

MuÑoZ, Fernando, "Ciudadanía laboral: crítica y defensa de un concepto jurídico-político”, Revista de Derecho, Chile, núm. 2, 2013.

NAVArRo, Federico, Los derechos de participación de los trabajadores en el nuevo escenario del derecho del trabajo en España, España, Tirant lo Blanch, 2015.

Organización InTERnACIONAL DEL TRABAjO, Informe de la Comisión de Expertos en Aplicación de Convenios y Recomendaciones, Informe III, Parte 1 A, Suiza, OIT, 2017.

Organización InTERnACIONAL DEL Trabajo, La Libertad Sindical. Recopilación de decisiones y principios del Comité de Libertad Sindical del Consejo de Administración de la OIT, 5a. versión revisada, Suiza, 2006.

PALOMO, Rodrigo, "El nuevo derecho de información de los sindicatos. Un ejemplo de reforma en la periferia del modelo", en ARELLANO, Pablo et al., Reforma al derecho colectivo del trabajo. Examen crítico de la Ley núm. 20.940, Chile, Thomson Reuters, 2016.

PALOMO, Rodrigo, "El sistema de garantías y facilidades para el ejercicio de la función sindical. Comentarios desde un enfoque dogmático y de derecho comparado", en PALOMO, Rodrigo (coord.), La organización sindical en Chile, Chile, Librotecnia, 2014.

PALOMO, Rodrigo, "Expectativa vs. realidad en la reforma laboral chilena. El nuevo derecho de información de los sindicatos como paradigma de una reforma transaccional", Derecho Laboral, Uruguay, núm. 263, 2016.

PALOMO, Rodrigo, "Los comités de empresa europeos y su implantación en España. Un modelo de reconocimiento avanzado de derechos de información y consulta en empresas con dimensión comunitaria", Ius et Praxis, Chile, núm. 22, 2016. 
PÉREZ, Francisco, Derechos de información sobre empleo y contratación. Los derechos de los representantes de los trabajadores en la empresa, según la Ley 2/1991, España, Bosch, 1993.

ROJAS, Irene y TAPIA, Francisco, "Las relaciones laborales colectivas en Chile", en MANGARELLI, Cristina et al., (coord.), Las relaciones laborales colectivas en América Latina y España, España, Tirant Lo Blanch, 2015.

SÁEZ, Carmen, Representación y acción sindical en la empresa, España, Ministerio de Trabajo y Seguridad Social, 1992.

SARTHOU, Helios, Trabajo, derecho y sociedad. Estudios de derecho colectivo del trabajo, Uruguay, Fundación de Cultura Universitaria, 2004, t. I.

SEverín, Juan Pablo, "Los sujetos de la negociación colectiva y la titularidad sindical", en ARELlano, Pablo et al., Reforma al derecho colectivo del trabajo. Examen crítico de la Ley núm. 20.940, Chile, Thomson Reuters, 2016.

SQUiRE, Nicholas et al., Informing and Consulting Employees. The New Law, Nueva York, Oxford University Press, 2009.

Toledo, César, Tutela de la Libertad Sindical, Chile, Abeledo Perrot, 2013.

VALDÉS, Fernando, "Una silenciosa pero incisiva reforma: el reforzamiento de los derechos de información y consulta", Relaciones Laborales, España, núm. 11, vol. 1, 2008.

VAlverde, Antonio, "Protección de datos de carácter personal y derechos de información de los representantes de los trabajadores", Temas Laborales, España, núm. 118, 2013.

VÁSQUEZ, Felipe, "La información a los representantes de los trabajadores. Fines y claroscuros en su aplicación”, Relaciones Laborales, España, núm. 18, 2010.

VillaViCENCIO, Alfredo, "Luces y sombras del arbitraje en la negociación colectiva", en AA.VV., VI Congreso Nacional de Derecho del Trabajo y de la Seguridad Social, Perú, Sociedad Peruana de Derecho del Trabajo y de la Seguridad Social, 2014.

ZAPIRAIN, Héctor, Derecho de información y negociación colectiva, Uruguay, Fundación de Cultura Universitaria, 2006.

ZAVALA,Jaime y VILCHEZ, Lidia, “¿Es tan peligroso proporcionar información empresarial en el marco de la negociación colectiva? El derecho de información como mecanismo de solución de conflictos laborales", Análisis Laboral, Perú, núm. 406, 2011. Vु 